\title{
St. Petersburger Ophthalmologische Gesellschaft
}

\section{Sitzung am 1. Mai 1903}

Bellarminof, Ein grosser Fremdkörper in der Augen-höhle. Am 22. Oktober 1902 stiess ein 12jähriger Knabe mit dem rechten Auge gegen ein Brett und Yerletzte sich nicht unerheblich am inneren Augenwinkel. Zwei Stunden nach der Verletzung Besichtigung und Verband. Ein Fremdkörper wurde nicht nachgewiesen. Bis zum 19. November keine Besserung; die Wunde heilt nicht, Lidödem, Eiterung. Das Auge ist nach Yorne und aussen Yerdrängt. Am inneren Augenwinkel unter der Bindehaut des oberen Lides ein Granulations-pfropfen und darunter eine Fistelöffnung, aus welcher spärlich Eiter austritt. Visus = 2/3. Es wird ein Fremdkörper Yermutet. Am õ. Dezember sieht Bellarminof den Knaben zum ersten Male. Eine ein-geführte Sonde dringt tief hinein, ein Fremdkörper liess sich aber nicht fiihlen. Am 18. Dezember wird die Sondierung wiederholt, gibt aber keinen Fremdkörper. Patient wird am 16. Januar 1903 aus der Klinik entlassen. Dauernd werden feuchte Kompressen appliziert. Am 2. März bemerkt die Mutter beim Verbandwechsel in der Wunde einen IIolz-splitter und entfernt denselben mit den Fingern. Das ausgestossene IJolzstück ist $18 \mathrm{~mm}$ lang und $9 \mathrm{~mm}$ breit, dabei zwischen 2 und 1 mm dick mit scharfer Spitze. Der Áusgang war Yollkommene Ileilung.

A. Lot in: Gumma der Sklera. Demonstration mikroskopischer Präparate.

A. Lotin: Melano-Sarcoma des unteren Lides. Demonstration mikroskopischer Präparate. W. Witzinski: Über die Wirkung des Bro m-Methyl-Atropin auf das Auge. Er bringt eine $\lambda^{\wedge}$ ersuchsreihe von mehr als 150 Fallen. Fine 1ì̀ bis 2 pCt. Lösung Yerursacht ganz* vorübergehend leichtes Brennen im Auge. In 20 bis 30 Minuten tritt die Erweiterung 184

ïherapeutische Umscliau.

der Pupille ein. Die maximale Erweiterung halt 4 bis 5 Stunden an, und am 4. Tage ist die Wirkung geschwunden. Mit Cocain zusammengegeben wirkt es schneller, ausgiebiger, und halt die Wirkung bis zu7 Tagen an. Die Akkommodation wird aufgehoben. Der Augendruckwird nicht beeinflusst. Es wirkt also schwächer als Atropin. Vielleichtist es brauclíbar in Fallen, $\lambda$ vo gewölmliches Atropin nicht vertragenwird. German n.

Therapeutische Umschau.

Über Abschabung von Hornhautflecken. •von Hohenstein-Malmö.

(Klin. Monatsbl. f. Augenheilk.)

Als Ausnahme-Behandlung für diffuse, oberflächliche Hornhaut-ñecke mit höckeriger, unregelmässiger Oberfläche bringt II. von neuem die Abrasio corneae in Erinnerung. Mit einem feinen Löffel wird der zentrale Teil der Hornhaut soweit abgeschabt, bis er von oberflächlichen Trübungen befreit und bei fokaler Beleuchtung ganz eben und glatt erscheint. Binnen 48 Stunden ist der Defekt gewöhnlich epithelisiert und die anfangs oft schwere Reizung geht schnell zurück. Nach-behandlung mit warmen Umschlägen, Massage, Dampfspray u. s. w. Die günstigen Resultate einer solchen Abrasio werden eingehend an drei Fallen illustriert. - Verf. kann genaue Indikationen nicht geben, doch dürfte der Eingriff Erfolg versprechen, wo die Sehstörung 
weniger von der Dichtigkeit der Trübungen, als von dem durch sie bedingten starken und unregelmässigen Hornhautastigmatismus abhängig ist.

Astigmatismus der Hornhaut und zentrale Chorioiditis der Myopen. von Senn-Wyl. (Ophthalm. Klinik No. 1. 1904.)

S. geht hier besonders auf die therapeutische Seite seiner im Archiv f. Augenheilkunde, Band XLVIII, 3. Heft, erschienenen Arbeit gleichen Namens ein, auf $\Lambda$ velche im übrigen verwiesen werden muss. „Die therapeutische Bedeutung der Frage liegt einerseits in der Prophylaxe durch frülizeitige Korrektion des Astigmatismus, andererseits bei schon €ingetretener Erkrankung in der Kombination der lokalen Behandlung durch subkonjunktivale Injektionen von Quecksilberlösungen mit der nach-folgenden gewissenhaften Korrektion des Astigmatismus." Bezüglich der Prophylaxe hat S. keinen der yon ihm korrigierten kombinierten Myopen an zentraler Chorioiditis erkranken gesehen (Be-obachtungsdauer 9 Jahre). Dabei wird in alien Fallen, welche beiderseits ungleich stark myopisch sind oder nicht von vornherein die passende $<$ jläserkorrektion voll annehmen, eine ausgiebige Atropinkur mit nach-folgender peinlich genauester Korrektion eingeleitet. - Bei schon einge-tretener zentraler Erkrankung wurde in 22 Fallen, welche durchschnittlich 2,8 Jahre in Beobachtung sind, nur eine durchschnittliche Refraktions-zunahme von 0,19 D und keine Visusabnahme, sondern eine durchschnittliche Visuszunahme von 0,05 festgestellt.

D. Die lokale Behandlungsmethode

$\Lambda$ velche in den meisten Fallen der Korrektion des Astigmatismus vorausgehen sollte besteht in sub-konjunktivalen Injektionen einer Hydrarg. oxycyanat.-Lösung 1: 5000. 